\title{
Antioxidants as effective remedies at hepatotoxic action of carbon tetrachloride
}

\author{
Karlen Hovnanyan ${ }^{1^{*}}$, Vardan Mamikonyan ${ }^{2}$, Anahit Margaryan $^{3}$, Kristine Sargsyan $^{1}$, \\ Margarita Hovnanyan $^{1}$, Maria Karagyozyan ${ }^{2}$, Konstantin Karageuzyan ${ }^{2}$ \\ ${ }^{1}$ Institute of Molecular Biology, Yerevan, Armenia; ${ }^{*}$ Corresponding Author: hovkarl@mail.ru \\ ${ }^{2}$ Scientific and Technological Center of Organic and Pharmaceutical Chemistry, NAS RA, Yerevan, Armenia \\ ${ }^{3} \mathrm{H}$. Buniatian Institute of Biochemistry, NAS RA, Yerevan, Armenia
}

Received 29 July 2013; revised 29 August 2013; accepted 5 September 2013

Copyright (C) 2014 Karlen Hovnanyan et al. This is an open access article distributed under the Creative Commons Attribution License, which permits unrestricted use, distribution, and reproduction in any medium, provided the original work is properly cited. In accordance of the Creative Commons Attribution License all Copyrights (C) 2014 are reserved for SCIRP and the owner of the intellectual property Karlen Hovnanyan et al. All Copyright (C) 2014 are guarded by law and by SCIRP as a guardian.

\section{ABSTRACT}

The liver, as the central metabolic organ, plays an important role in metabolism of carbohydrates, lipids and proteins. In the environment, there are many hepatotoxic xenobiotics. $\mathrm{CCl} 4$ is a free radical toxic for organelles of hepatocytes. The presented work was studying the character of ultrastructural changes in $\mathrm{CCl} 4$-intoxicated hepatocytes as well as the tissue after treatment by grape seed extract (GSE), $\alpha$-tocopherol $(\alpha-T)$. As a result of cell bioremediation effect and reactions against corruptive factors, the liver has a high regeneration ability.

\section{KEYWORDS}

\section{CCI4; GSE; $\alpha$-Tocopherol; Ultrastructural Changes; Intoxicated Hepatocytes; Electron Microscopy}

\section{INTRODUCTION}

The liver, as human organ with high metabolic activity, plays an important role in metabolism of carbohydrates, lipids and proteins. As a result of cell protective cooperation and reactions against corruptive factors, liver also has a high regeneration ability [1,2]. In spite of considerable progress in hepatology [3-5], the study of corruption and regeneration mechanisms of hepatocytes on tissue, cellular and molecular levels remains to be very actual. Among toxins, which are widely used for modulating some damage of liver (liver cirrhosis-LC, hepatitis), the most popular is carbon tetrachloride (CCl4) [6].

Aim of the presented work was to study the character of ultrastructural changes in CCl4-intoxicated hepatocytes as well as the tissue after treatment by grape seed extract (GSE), $\alpha$-tocopherol ( $\alpha$-T), as potential prophylaxis and treatment agents with antioxidant action at liver injury, mainly in experimental model of LC.

\section{MATERIAL AND METHODS}

\subsection{Experimental and Preparation to Assays}

In this study, we used white male rats weighting between 180 - $200 \mathrm{~g}$, which were subdivided into four groups: I-control group (intact animals); II-group, animals with experimental liver damages; III-group, animals with experimental liver damages with GSE injection; IV-group, animals whit experimental liver damages with $\alpha$-T. We induced liver damages by intraperitoneal injection of CCl4 at a dose of $150 \mu \mathrm{g}$ per $100 \mathrm{~g}$ of body weight.

\subsection{Electron Microscopy Assays}

For transmission electron microscope study we use liver tissue examples from control group as well as from experimental groups after CCl4, GSE, $\alpha$-T influence. Preliminary fixation of the samples was carried out in $2.5 \%$ glutaraldehyde solution in phosphate buffer, and post fixation-in $1 \%$ solution of osmium tetroxide in the same buffer [7]. The samples were dehydrated in ethanol solutions with increasing concentration, poured and soaked by araldite mixtures of resins. After polymerization, ultrathin sections were prepared for microtome "Reichert-Ultracut" consistent with their staining solution uranyl acetate and lead citrate [8].

The study of made preparations and them pho- 
tomicrography was carried out using a transmission electron microscope “Tesla BS-500” in a voltage of $80 \mathrm{kV}$.

\section{RESULTS AND DISCUSSION}

Ultrastructural analysis of hepatocytes in the control group white rats liver has set a characteristic feature of hepatocytes expressed the depositors function. In the cytoplasm we can see a large number of polysomes, granular endoplasmic reticulum, vesicles, rosette-shaped glycogen granules, which are found in the area of lipid droplets without bounding membranes, lysosomes, rarely orthodox configuration mitochondria with the normal structure of the matrix and crista as well as heterochromatin and nucleolus in the nucleus of hepatocytes, granular-fibrillar structure with normal configuration of sinusoidal capillaries, the structure of Kupffer cells and space of Disse (Figures 1(a) and (b)).

Electron microscopic study of the liver of albino rats after induction of liver toxicity revealed nonspecific damage of the mitochondrial membrane, mitochondrial swelling with fragmentation and destruction of their

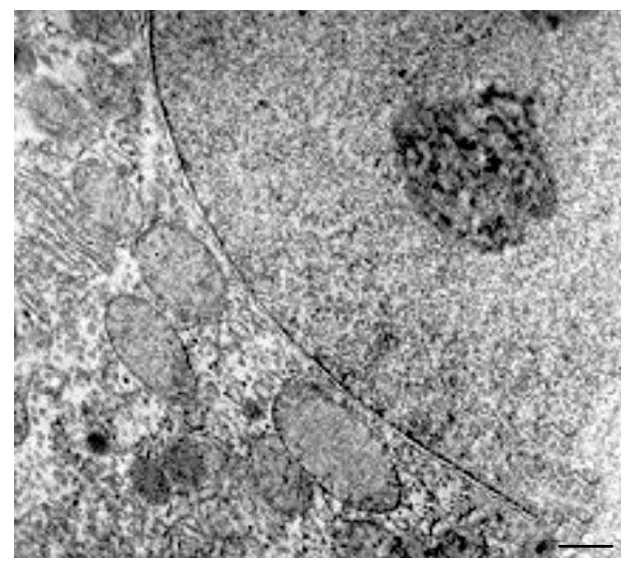

(a)

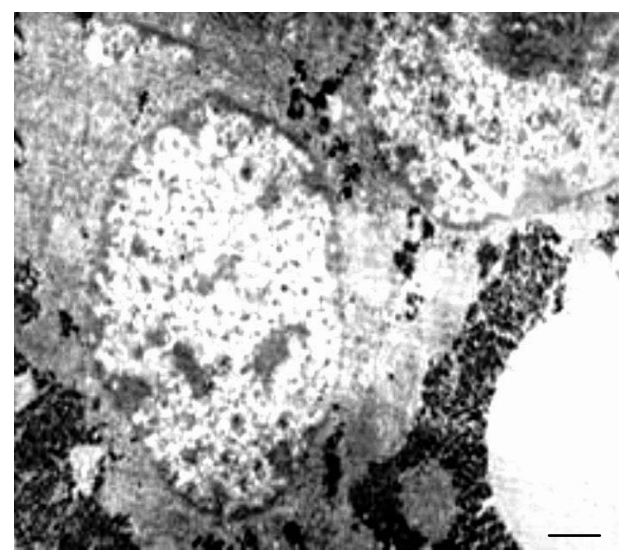

(b)

Figure 1. (a), (b) White rat hepatocytes (control group). TEM. Ultrathin section. Scale bare $=1$ $\mu \mathrm{m}$. crista (Figure 2(a)). In the cytoplasm of hepatocytes observed vesiculation, expansion of tanks of the endoplasmic reticulum and perinuclear space with a pyknotic changed nucleus and marginated chromatin. (Figure 2(a)), as well as hyperplasia of the granular endoplasmic reticulum (Figure 2(b)) and the simultaneous loss of ribosomes, which results in the transformation of granular endoplasmic reticulum in smooth (Figure 2(b)).

In the hepatocytes of the experimental animals in the areas of glycogen identified lipid droplets of various sizes and quantities, evidence of fat and vacuolar degeneration of the body. It was reveals a sharp expansion of sinusoidal space, increase in cellular structures of connective tissue, including collagen fibrils, bundles of which fill the intercellular space, indicating the onset of the initial stage of LC (Figure 3).

The ultrastructural changes are indicators of the activation energy, glycogen and protein synthesis processes in hepatocytes in response to a damaging factor [9].

GSE influence manifested itself in a protective-restorative effect on the ultrastructure of mitochondria with

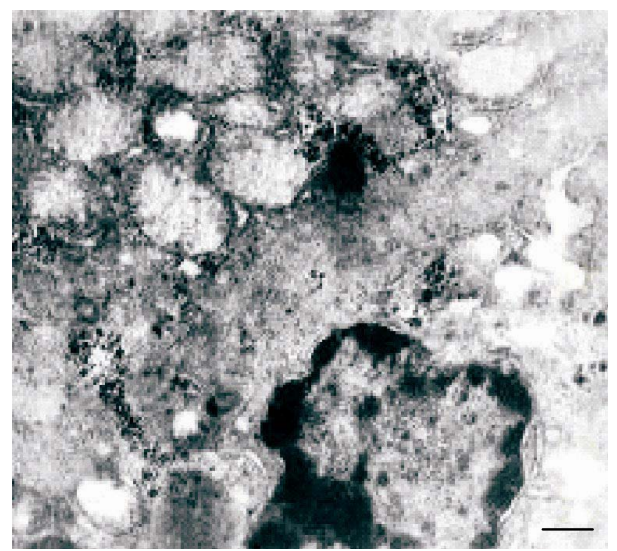

(a)

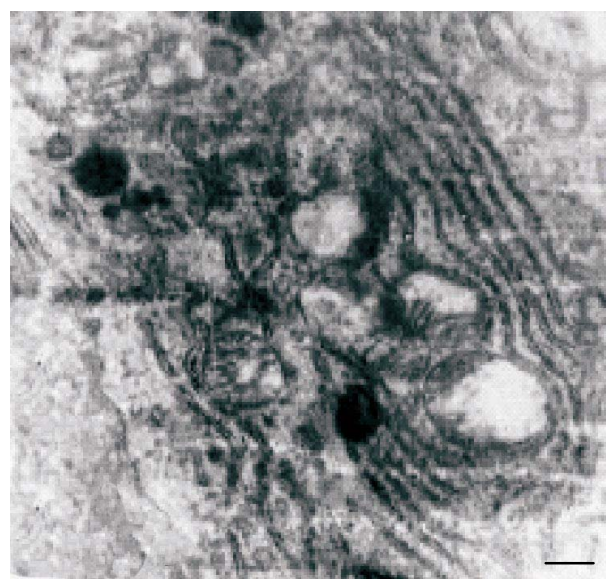

(b)

Figure 2. (a), (b) TEM. Experimental white rat hepatocytes with $\mathrm{CCl}_{4}$-intoxication. Ultrathin section. Scale bare $=1 \mu \mathrm{m}$. 
a decrease in the number of hepatocytes with lipid inclusions and vacuolization (Figures 4(a) and (b)).

The ultrastructure of hepatocytes and organization of sinusoidal cell space after GSE, as well as $\alpha$-T was closer to the picture of intact cells (Figure 5).

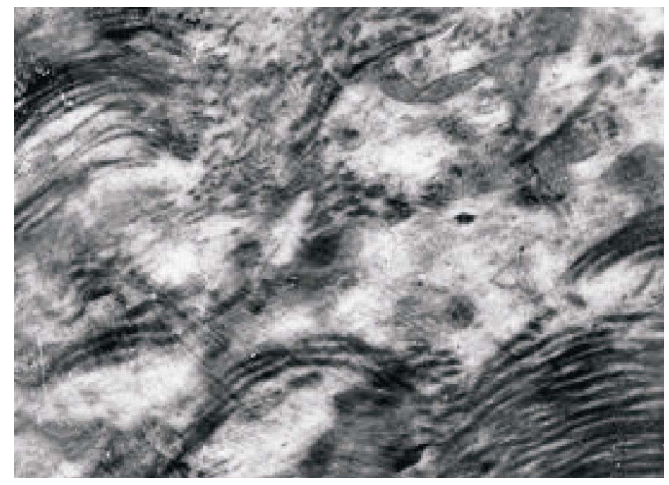

Figure 3. TEM. Experimental white rat hepatocytes with $\mathrm{CCl}_{4}$-intoxication. The initial stage of cirrhosis. Ultrathin section. Scale bare $=1 \mu \mathrm{m}$.

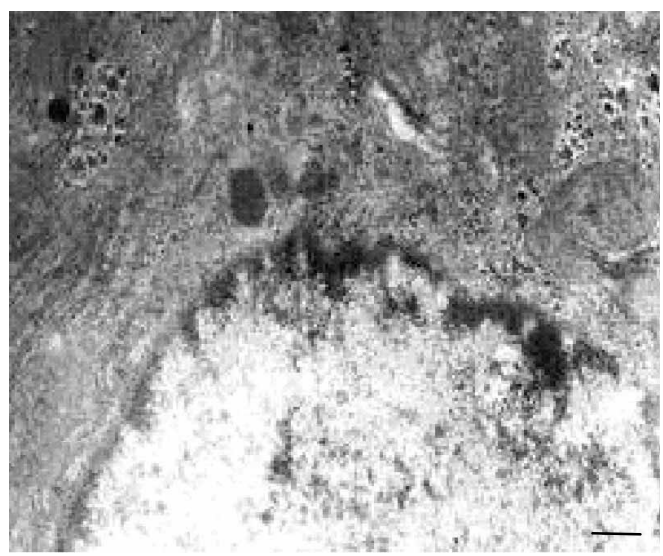

(a)

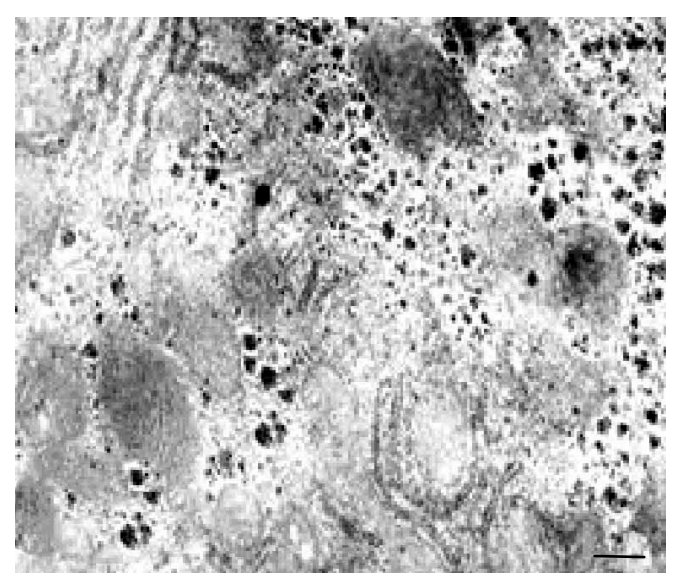

(b)

Figure 4. (a), (b) TEM. Experimental white rat hepatocytes by $\mathrm{CCl}_{4}$ intoxication after GSE injection (III group). Ultrathin section. Scale bare $=1$ $\mu \mathrm{m}$.

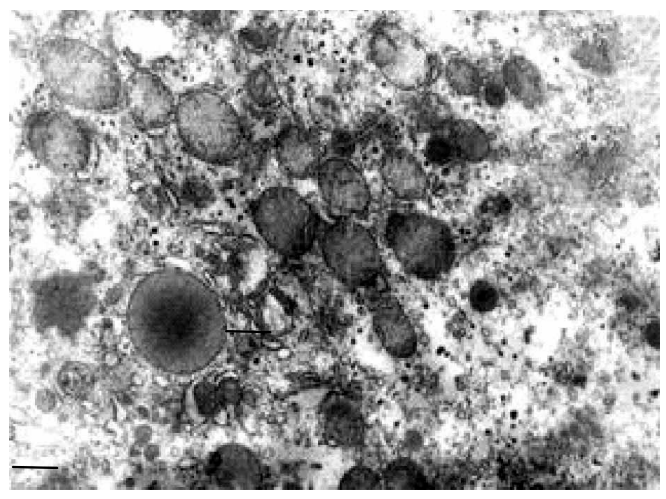

Figure 5. TEM. Experimental white rat hepatocytes intoxication with $\mathrm{CCl} 4$ after $\alpha$-T injection (IV group). Ultrathin section. Scale bare $=1 \mu \mathrm{m}$.

\section{CONCLUSIONS}

Thus, the model of liver toxicity and the LC, based on the nature of ultrastructural changes of mitochondria and other compartments of hepatocytes, GSE, as well as $\alpha$-T and STS, have corrective effect.

TEM ultrastructural characterization of the GSE influence is evidence of its success cytoprotective and antitoxic features as well as hepatocytes from xenobiotic$\mathrm{CCl} 4$ induced by cirrhosis rat liver.

\section{ACKNOWLEDGEMENTS}

The study was done within the framework supported by Ministry of Education and Science of the Republic of Armenia (Basic support).

\section{REFERENCES}

[1] Dzhivanyan, K.A. and Adamyan, N.V. (2001) About features of ultrastructure of a liver of birds in norm and after partial hepatoctomy. The Russian Morphological Sheets, Moscow, 3-4, 26-27.

[2] Fausto, N. and Campbell, J.S. (2003) The role of hepatocytes and oval cells in liver regeneration and repopulation. Mechanisms of Development, 120, 117-130.

http://dx.doi.org/10.1016/S0925-4773(02)00338-6

[3] Loginov, A.S. and Block, Yu.E. (1987) Chronical hepatitis and liver cirrhosis. Medicine, 272.

[4] Powell, E.E., Jonsson, J.R. and Clouston, A.D. (2005) Steatosis: Co-factor in other liver diseases. Hepatology, 42, 5-13. http://dx.doi.org/10.1002/hep.20750

[5] Simonyan, A.A., Margaryan, A.S., Hovnanyan, K.O., Asatryan, R.G. and Hovnanyan, M.K. (2007) Effect of antioxidants on white rats with liver intoxication induced by carbon tetrachloride: Ultrastructural analysis. Proceedings of the International Symposium under the Aegis of UNESCO "Problems of Biochemistry, Molecular and Radiation Biology and Genetics”, Yerevan, 2007, 74-75.

[6] Craciun, C., Ardelan, A., Ciobanu, C., Rusu, M.A., Puica, C., Tamas, M. and Craciun, V. (2004) Structural-funtional studies regarding the effect of Berberia vulgaris extract 
on rat intoxicated liver. Proceedings of 13th European Microscopy Congress, Antwerp, 3, 463-464.

[7] Sabatini, D.D., Bensch, K. and Barnett, R.J. (1963) Cytochemistry and electron microscopy-The preservation of cellular ultrastructure and enzymatic activity by aldehyde fixation. The Journal of Cell Biology, 17, 19-58.

[8] Venable, J.H. and Coggeshall, R. (1965) A simplified lead citrate stain for use in electron microscopy. The Journal of Cell Biology, 25, 407-408. http://dx.doi.org/10.1083/jcb.25.2.407

[9] Sarkisov, D.S. (1970) Regeneration and its clinical significance. Medicine, 281. 